\title{
Shift and broadening of hyperfine components of the first doublet of cesium perturbed by foreign gases
}

\author{
E. Bernabeu and J. M. Alvarez \\ Departamento de Física Fundamental, Cátedra de Optica, Facultad de Ciencias, Universidad de Zaragoza, Spain \\ (Received 18 December 1979)
}

\begin{abstract}
The collision broadening and shift of the hyperfine structure components of the ground-state splitting for the $D_{1}$ (8943 $\AA$ ) and $D_{2}(8521 \AA)$ cesium lines by noble gases ( $\mathrm{He}, \mathrm{Ne}, \mathrm{Ar}, \mathrm{Kr}$, and $\mathrm{Xe}$ ) and by light molecular gases $\left(\mathrm{H}_{2}\right.$ and $\left.\mathrm{N}_{2}\right)$ under pressures not greater than 150 Torr and at a temperature of $295 \mathrm{~K}$ are investigated. The Lennard-Jones (12-6) interatomic potential constants are calculated for these systems, using the semiclassical theory of Lindholm-Foley (for $\mathrm{Cs}$ with $\mathrm{Ne}, \mathrm{Ar}, \mathrm{Kr}, \mathrm{Xe}$, and $\mathrm{N}_{2}$ systems) and the quantum theory of Baranger (for $\mathrm{Cs}$ with $\mathrm{He}$ and $\mathrm{H}_{2}$ systems), by comparing with our experimental results in fine structure. These potential constants are employed for the determination of the shift and broadening in hyperfine structure, using the hyperfine theory of collision broadening.
\end{abstract}

\section{INTRODUCTION}

The spectral lines of an atom experience modifications in their profiles when the atom is perturbed by the presence of other atoms or molecules. ${ }^{1}$ A great many experimental studies of the shift, broadening, and asymmetry of the first resonance doublets of cesium perturbed by foreign gases have been made. ${ }^{2}$ But there are few experimental results of the hyperfine structure of cesium: The broadening of the $4555 \AA$ line by argon ${ }^{3}$ and of the second doublet ( $\lambda=4555$ and $4593 \AA$ ) by helium, argon, and xenon ${ }^{4}$ have been investigated. $T$ he broadening and shift of this doublet has been measured under pressure of neon, argon, and xenon. ${ }^{5}$ For the first doublet we have measured the shift of the hfs (hyperfine-structure) components of the ground state for the $D_{1}(8943 \AA)$ and $D_{2}$ $(8521 \AA$ ) lines in the presence of noble gases and light molecular gases (hydrogen, nitrogen) at pressures not greater than $150 \mathrm{~T}$ orr. The results for the light noble gases helium, neon, and argon have been reported in a previous paper. ${ }^{6}$

In this paper we present our measurements for krypton, xenon, hydrogen, and nitrogen as foreign gases as well as new values for helium, neon, and argon. These latter values correspond to the ones previously reported by $u^{6}{ }^{6}$ corrected with a more accurate deconvolution method of the instrumental function from the experimental profiles. The method is described in this paper. We also present here the values of the interatomic potential constants for cesium-noble gas and cesium-light molecular gas, calculated for a Lennard-Jones (12-6) potential using the shift and broadening in fine structure, derived from our experimental results in hfs. Moreover, we have calculated with these interatomic potential the shift and broadening of the hfs components of the $D_{1}$ line.

\section{EXPERIMENTAL METHOD}

The absorption coefficient of the cesium vapor with and without foreign gas has been measured in order to make a comparative study on the influence of the foreign gases. The profile of the absorption coefficient has been obtained by the double measurement method, ${ }^{6}$ which allows the obtaining of comparable emission and transmission recordings with a common origin. One can obtain the $\alpha(\sigma)$ absorption coefficient profiles by the expression

$$
\alpha(\sigma)=(1 / l) \ln \left[I_{0}(\sigma) / I(\sigma)\right],
$$

where $l$ is the length of the absorption cell, $I(\sigma)$ and $I_{0}(\sigma)$ are the spectral distributions of the transmitted and emitted light, respectively. These spectral distribution profiles were measured with a piezoelectrically scanned Fabry-Perot spectrometer with synchronous detection, described in Ref. 6.

For small absorption, such that $X l \leqslant 0.4$, the absorption coefficient can be expressed by a convolution of the instrumental function of the spectrometer $W(\sigma)$, and the true absorption coefficient $X(\sigma)$ (Ref. 7).

$$
\alpha(\sigma)=W(\sigma) \otimes X(\sigma) ;
$$

in our case $X l \sim 0.3$, so that the condition is fulfilled.

The true absorption coefficient is the convolution of the $D(\sigma)$ inhomogeneous process function (Doppler broadening) and the $\pi(\sigma)$ homogeneous process function (pressure effects, resonant broadening, and natural width). Therefore, if the Doppler broadening is a Gaussian function and $\pi(\sigma)$ is a Lorentzian function, the experimental absorption coefficients may be considered as Voigt profiles. Moreover, the instrumental function $W(\sigma)$ of our Fabry-Perot spectrometer may be approximated 


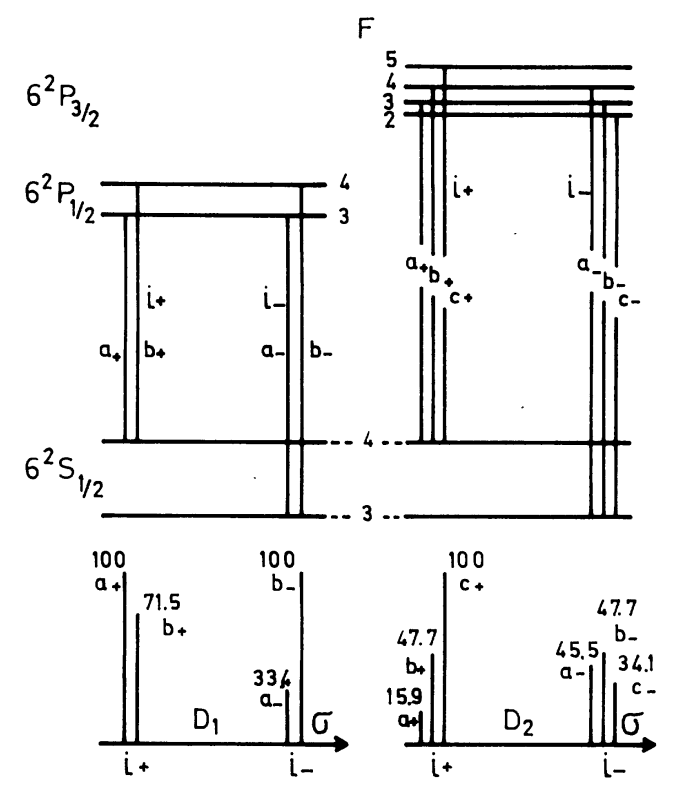

FIG. 1. Hyperfine pattern of $6^{2} S_{1 / 2}-6^{2} P_{1 / 2}, 6^{2} S_{1 / 2}$ $6^{2} P_{3 / 2}$ transition. The theoretical intensity is given for each of their hyperfine components.

by a Voigt function, and an experimental determination of this function has been made by us. ${ }^{8}$ The instrumental function for the first optical doublet of cesium is characterized by the following widths:

\section{Instrumental Voigt function}

width $\left(10^{-3} \mathrm{~cm}^{-1}\right)$

Lorentzian component

Gaussian component
$\mathrm{D}_{1} \quad \mathrm{D}_{2}$

$49.1 \quad 51.1$

$10.3 \quad 10.3$

$43.3 \quad 45.3$
Finally, with these considerations the experimental absorption coefficient can be expressed by means of a Voigt function.

To obtain the homogeneous process contribution $\pi(\sigma)$, one must perform deconvolution of $\pi(\sigma)$, $W(\sigma)$, and $D(\sigma)$. We have used a deconvolution method consisting in applying an analytic approximation to the Voigt function. ${ }^{9}$ Pyrex glass absorption cells of $5-\mathrm{cm}$ width with cesium and foreign gases at pressures of $10,20,50,100$, and 150 Torr were used. The measurements were made for a temperature of $295 \pm 1 \mathrm{~K}$.

\section{RESULTS}

We have determined the shift and broadening of the hfs components $\left(i_{+}, i_{-}\right)$corresponding to the ground-state splitting of the $D_{1}, D_{2}$ lines of cesium (Fig. 1), starting from the experimental absorption coefficients for the test cells of cesium-buffer gas. The absorption coefficient of a gasless cesium cell has been taken as a reference.

As the hfs components $\left(i_{+}, i_{-}\right)$of the $D_{1}, D_{2}$ lines are complex spectral lines, it has been necessary to carry out an analysis of the absorption coefficient profiles. ${ }^{7}$ The absorption coefficient of the gasless cesium cell (reference coefficient) for each hfs component $\left(i_{+}, i_{-}\right)$of the lines $D_{1}, D_{2}$ is obtained by the addition of the absorption coefficient of hfs components corresponding to the excited state. For the hfs components $i_{+}, i_{-}$of the line $D_{2}$, the width of the absorption coefficient of each hfs component $a_{ \pm}, b_{ \pm}, c_{ \pm}$is $\sim 52.8 \times 10^{-3} \mathrm{~cm}^{-1}$; much higher than the hfs splitting of the centers of gravity of the $a_{ \pm}, b_{ \pm}$, $c_{ \pm}$components $\left(\sim 7.6 \times 10^{-3} \mathrm{~cm}^{-1}\right)$. In this case the absorption coefficient of the components $i_{+}, i_{-}$of the line $D_{2}$ can be considered as a Voigt profile. ${ }^{10}$ For the line $D_{1}$, the width of the absorption coefficient of the hfs components $a_{ \pm}, b_{ \pm}$is $\sim 50.7 \times 10^{-3}$ $\mathrm{cm}^{-1}$; it is of the same order as the hfs splitting of the centers of gravity $\left(\sim 40.6 \times 10^{-3} \mathrm{~cm}^{-1}\right)$. E ach one of the components $i_{+}, i_{-}$of the line $D_{1}$ is then obtained by addition of two shifted Voigt profiles.

The Voigt profile corresponding to the hfs components $\left(a_{t}, b_{t}, c_{t}\right)$ of the absorption coefficient has a Gaussian component, which is the sum of the Doppler broadening and the Gaussian component of the instrumental function. For our experimental conditions, the Lorentzian component is the sum of the natural width ${ }^{11}\left(\sim 10^{-3} \mathrm{~cm}^{-1}\right)$, the resonant broadening $\left[\sim 10^{-7} \mathrm{~cm}^{-1}\right.$, for an atomic density of $3 \times 10^{14}$ atom $\mathrm{cm}^{-3}$ at $T=295 \mathrm{~K}$ (Ref. 12)], and the Lorentzian component of the instrumental function.

The analysis of the hfs components $i_{+}, i_{-}$of the absorption coefficient of cesium with gas cells has been made by fitting to each component $i_{+}, i_{-}$a Voigt profile for the line $D_{2}$, and an addition of two Voigt profiles for the line $D_{1}$. The Lorentzian contribution, due only to broadening by pressure, is obtained by deconvolution of the absorption coefficient of the cesium-gas system from the one of the gasless cesium. The shifts have been evaluated by considering the gravity center of the $i_{+}, i_{-}$ components of the absorption coefficient of cesium with gas respective to the gasless cesium.

The values obtained for the shift and broadening for each pressure value of the perturbing gases have been fitted by a least-squares method to a straight line, ${ }^{13}$ obtaining a standard deviation of the slope between 1.0 to $3.0 \%$. Each straight line crosses the origin. The values of the shifts and broadenings are given in Table I and Table II, respectively.

As our results are for hyperfine structure and those of other authors for fine structure, we thought it was useful to calculate the shift and 
TABLE I. Summary of results for the shifts of all hfs components of the $D_{1}, D_{2}$ lines of $C$ s in $\mathrm{He}, \mathrm{Ne}, \mathrm{Ar}, \mathrm{Kr}, \mathrm{Xe}, \mathrm{H}_{2}$, and $\mathrm{N}_{2}$.

\begin{tabular}{|c|c|c|c|}
\hline System & $\begin{array}{l}\text { hfs components of the } \\
\text { ground-state splitting }\end{array}$ & \multicolumn{2}{|c|}{ shift $\left(10^{-3} \mathrm{~cm}^{-1} /\right.$ Torr; $\left.T=295 \mathrm{~K}\right)$} \\
\hline \multirow[t]{2}{*}{$\mathrm{He}$} & $i_{+}$ & $0.17 \pm 0.03$ & $0.08 \pm 0.01$ \\
\hline & $i_{-}$ & $0.25 \pm 0.04$ & $0.18 \pm 0.04$ \\
\hline \multirow[t]{2}{*}{$\mathrm{Ne}$} & $i_{+}$ & $-0.09 \pm 0.02$ & $-0.10 \pm 0.01$ \\
\hline & $i_{-}$ & $-0.12 \pm 0.04$ & $-0.21 \pm 0.01$ \\
\hline \multirow[t]{2}{*}{ Ar } & $i_{+}$ & $-0.26 \pm 0.03$ & $-0.23 \pm 0.02$ \\
\hline & $i_{-}$ & $-0.32 \pm 0.03$ & $-0.28 \pm 0.03$ \\
\hline \multirow[t]{2}{*}{$\mathrm{Kr}$} & $i_{+}$ & $-0.09 \pm 0.05$ & $-0.28 \pm 0.02$ \\
\hline & $i_{-}$ & $-0.29 \pm 0.01$ & $-0.24 \pm 0.05$ \\
\hline \multirow[t]{2}{*}{$\mathrm{Xe}$} & $i_{+}$ & $-0.24 \pm 0.05$ & $-0.33 \pm 0.02$ \\
\hline & $i_{-}$ & $-0.30 \pm 0.03$ & $-0.26 \pm 0.03$ \\
\hline \multirow[t]{2}{*}{$\mathrm{H}_{2}$} & $i_{+}$ & $0.001 \pm 0.008$ & $-0.35 \pm 0.01$ \\
\hline & $i_{-}$ & $0.148 \pm 0.004$ & $0.46 \pm 0.01$ \\
\hline \multirow[t]{2}{*}{$\mathrm{N}_{2}$} & $i_{+}$ & $-0.21 \pm 0.02$ & $-0.18 \pm 0.07$ \\
\hline & $i$. & $-0.28 \pm 0.03$ & $-0.30 \pm 0.06$ \\
\hline
\end{tabular}

broadening in fine structure from our values in hfs. We have hence calculated the shifts of the centers of gravity of the $D_{1}, D_{2}$ lines, obtained by Jackson's method. ${ }^{14}$ We obtained the broadenings by the weighted mean of the broadenings of the hyperfine components $i_{+}, i_{-}$of each one of the lines. These values are shown in Table III together with those of other authors. These experimental and theoretical values correspond to a linear extrapolation to our experimental conditions from the values given by these authors for higher pressures, except for the values of Granier and collaborator $\mathrm{s}^{15}$ given for low pressure ( $\leqslant 3$ relative density). The extrapolation to the temperature range of interest in our measurements has been obtained using the expression given by Kielkopf. ${ }^{16}$

\section{INTERATOMIC POTENTIÁLS}

We present here the calculation of the interatomic potential constants for Cs-gas systems with a Lennard-J ones $\left(C_{12} r^{-12}-C_{6} r^{-6}\right)$ potential using our experimental results in fine structure. The Lindholm-Foley theory ${ }^{17}$ has been used to relate the shift $(\beta)$ and broadening $(2 \gamma)$ to the interatomic potential constants by the expressions ${ }^{18}$

$$
\begin{aligned}
& \beta=2 N \bar{v} \int_{0}^{\infty} \sin \eta(\rho) \rho d \rho, \\
& 2 \gamma=4 \pi N \bar{v} \int_{0}^{\infty}[1-\cos \eta(\rho)] \rho d \rho,
\end{aligned}
$$

where $\rho$ is the impact parameter of the collision, $\bar{v}$ is the mean relative velocity, $N$ is the number

TABLE II. Summary of results for the broadening of the hfs components of the ground-

\begin{tabular}{|c|c|c|c|}
\hline \multirow[b]{2}{*}{ System } & \multirow[b]{2}{*}{ hfs components } & \multicolumn{2}{|c|}{ Broadening $\left(10^{-3} \mathrm{~cm}^{-1} /\right.$ Torr; $\left.T=295 \mathrm{~K}\right)$} \\
\hline & & 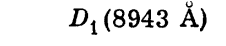 & $D_{2}(8521 \AA)$ \\
\hline \multirow[t]{2}{*}{$\mathrm{Cs}-\mathrm{He}$} & $i_{+}$ & $0.66 \pm 0.03$ & $0.92 \pm 0.05$ \\
\hline & $i$ & $0.62 \pm 0.06$ & $0.86 \pm 0.06$ \\
\hline \multirow[t]{2}{*}{$\mathrm{Cs}-\mathrm{Ne}$} & $i_{+}$ & $0.10 \pm 0.01$ & $0.39 \pm 0.04$ \\
\hline & $i$ & $0.57 \pm 0.04$ & $0.30 \pm 0.03$ \\
\hline \multirow[t]{2}{*}{ Cs-Ar } & $i_{+}$ & $0.69 \pm 0.03$ & $0.73 \pm 0.03$ \\
\hline & $i_{-}$ & $0.62 \pm 0.05$ & $0.79 \pm 0.02$ \\
\hline \multirow[t]{2}{*}{ Cs-Kr } & $i_{+}$ & $0.70 \pm 0.10$ & $0.40 \pm 0.04$ \\
\hline & $i_{-}$ & $0.61 \pm 0.06$ & $0.33 \pm 0.02$ \\
\hline \multirow[t]{2}{*}{$\mathrm{Cs}-\mathrm{Xe}$} & $i_{+}$ & $0.74 \pm 0.11$ & $1.89 \pm 0.10$ \\
\hline & $i_{-}$ & $0.69 \pm 0.06$ & $1.95 \pm 0.30$ \\
\hline \multirow[t]{2}{*}{$\mathrm{Cs}-\mathrm{H}_{2}$} & $i_{+}$ & $1.44 \pm 0.28$ & $2.00 \pm 0.32$ \\
\hline & $i_{-}$ & $1.25 \pm 0.13$ & $1.98 \pm 0.21$ \\
\hline \multirow[t]{2}{*}{$\mathrm{Cs}-\mathrm{N}_{2}$} & $i_{+}$ & $1.01 \pm 0.33$ & $1.19 \pm 0.22$ \\
\hline & $i_{-}$ & $1.02 \pm 0.13$ & $1.38 \pm 0.31$ \\
\hline
\end{tabular}
state splitting of the $D_{1}, D_{2}$ lines of $\mathrm{Cs}$ in $\mathrm{He}, \mathrm{Ne}, \mathrm{Ar}, \mathrm{Kr}, \mathrm{Xe}, \mathrm{H}_{2}$, and $\mathrm{N}_{2}$. 
TABLE III. Shift $(\beta / N)$ and broadening $(\gamma / N)$ constants for $D_{1}, D_{2}$ lines of the Cs in He, Ne, $\mathrm{Ar}, \mathrm{Kr}, \mathrm{Xe}, \mathrm{H}_{2}$, and $\mathrm{N}_{2}$. $\left(\beta / N\right.$ and $\gamma / N$ are in units for $\left.10^{-21} \mathrm{~cm}^{-1}\left(\text { atom } / \mathrm{cm}^{3}\right)^{-1}\right)$. (ist denotes isotropic potential; ans, anisotropic potential).

\begin{tabular}{|c|c|c|c|c|c|}
\hline \multirow{2}{*}{$\begin{array}{l}\text { Perturbing } \\
\text { gas }\end{array}$} & \multicolumn{2}{|c|}{$D_{1}(8943 \AA)$} & \multicolumn{2}{|c|}{$D_{2}(8521 \AA)$} & \multirow[b]{2}{*}{ References } \\
\hline & $\beta / N$ & $\gamma / N$ & $\beta / N$ & $\gamma / N$ & \\
\hline $\mathrm{He}$ & $\begin{array}{c}6.72 \pm 1.02 \\
7.18 \\
4.76 \\
0.616 \\
12.95\end{array}$ & $\begin{array}{c}19.49 \pm 1.37 \\
24.18 \\
26.01 \\
15.78 \\
20.47\end{array}$ & $\begin{array}{l}3.94 \pm 1.71 \\
\quad 1.14 \\
0.56 \\
0.616\end{array}$ & $\begin{array}{c}27.20 \pm 1.72 \\
24.18 \\
24.05 \\
15.78\end{array}$ & $\begin{array}{l}\text { Present work } \\
\text { S. Y. Ch'en } \\
\text { Ref. } 2\left(\text { (b) }^{\mathrm{a}}\right. \\
\text { Ref. } 16^{\mathrm{b}} \\
\text { Ref. } 23(\mathrm{~b})^{\mathrm{b}}\end{array}$ \\
\hline $\mathrm{Ne}$ & $\begin{array}{c}-2.93 \pm 0.09 \\
-1.86 \\
-4.40\end{array}$ & $\begin{array}{c}10.29 \pm 0.87 \\
8.78 \\
8.41\end{array}$ & $\begin{array}{c}-4.33 \pm 0.33 \\
-3.72 \\
-4.40\end{array}$ & $\begin{array}{c}10.51 \pm 1.10 \\
8.78 \\
8.41\end{array}$ & $\begin{array}{l}\text { Present work } \\
\text { Ref. } 2(\mathrm{~d})^{\mathrm{a}} \\
\text { Ref. } 16^{\mathrm{b}}\end{array}$ \\
\hline Ar & $\begin{array}{c}-8.87 \pm 0.41 \\
-8.85 \\
-6.28 \\
-7.44\end{array}$ & $\begin{array}{c}20.13 \pm 0.23 \\
21.22 \\
19.16 \\
\\
29.75\end{array}$ & $\begin{array}{c}-7.54 \pm 0.33 \\
-7.99 \\
-6.28 \\
-7.88 \\
-4.91 \\
-6.40\end{array}$ & $\begin{array}{l}23.21 \pm 0.11 \\
21.22 \\
19.16 \\
21.20 \\
\\
19.32 \\
22.69\end{array}$ & $\begin{array}{l}\text { Present work } \\
\text { Ref. } 2\left(\text { a }^{\text {a }}\right. \\
\text { Ref. } 16^{\text {b }} \\
\text { S. Y. Ch'en } \\
\text { Ref. } 23 \text { (b) }{ }^{\text {b,c }} \\
\text { Ref. } 15^{\text {b (ist) }} \text { (ans) }\end{array}$ \\
\hline $\mathbf{K r}$ & $\begin{array}{c}-2.69 \pm 0.1 \\
-7.44 \\
-7.44 \\
-6.28 \\
-4.48\end{array}$ & $\begin{array}{c}20.16 \pm 2.59 \\
10.41 \\
18.60 \\
19.02 \\
17.85\end{array}$ & $\begin{array}{c}-8.10 \pm 1.13 \\
-7.81 \\
-7.44 \\
-6.28 \\
-4.07 \\
-5.02\end{array}$ & $\begin{array}{c}11.18 \pm 0.98 \\
10.42 \\
18.60 \\
19.02 \\
17.48 \\
18.97\end{array}$ & $\begin{array}{l}\text { Present work } \\
\text { Ref. 2(c) } \\
\text { J. Duperier } \\
\text { Ref. } 16^{\mathrm{b}} \\
\text { Ref. } 15^{\text {b }} \text { (ist) }_{\text {(ans) }}\end{array}$ \\
\hline $\mathrm{Xe}$ & $\begin{array}{c}-8.42 \pm 1.11 \\
-9.30 \\
-11.90 \\
-8.55 \\
-6.96 \\
-5.21\end{array}$ & $\begin{array}{c}21.84 \pm 2.64 \\
18.23 \\
31.99 \\
18.60 \\
20.95 \\
22.98\end{array}$ & $\begin{array}{c}-9.07 \pm 0.84 \\
-9.29 \\
-8.56 \\
-6.96 \\
-5.32 \\
-5.09\end{array}$ & $\begin{array}{c}58.62 \pm 6.26 \\
8.55 \\
\\
18.60 \\
20.95 \\
22.95 \\
20.35\end{array}$ & $\begin{array}{l}\text { Present work } \\
\text { Ref. } 2(\mathrm{e}) \text { and } 2(\mathrm{f})^{\mathrm{a}} \\
\text { Ref. } 23(\mathrm{a})^{\mathrm{b}} \\
\text { Ref. } 2(\mathrm{c})^{\mathrm{a}} \\
\text { Ref. } 16^{\mathrm{b}} \\
\text { Ref. } 15^{\text {b (ist) }} \text { (ans) }\end{array}$ \\
\hline $\mathrm{H}_{2}$ & $2.29 \pm 0.19$ & $41.08 \pm 6.30$ & $1.81 \pm 0.26$ & $47.44 \pm 8.10$ & Present work \\
\hline $\mathrm{N}_{2}$ & $\begin{array}{c}-7.38 \pm 0.11 \\
-6.42\end{array}$ & $30.93 \pm 5.71$ & $-7.25 \pm 0.24$ & $39.38 \pm 9.73$ & $\begin{array}{l}\text { Present work } \\
\text { E. Bernabeu }\end{array}$ \\
\hline
\end{tabular}

${ }^{a}$ Experimental value.

b Theoretical value.

${ }^{\mathrm{C}} \mathrm{S}$. Y. Ch'en, in Proceedings of the Intermational Conference on Optical Pumping and Atomics Lines Shape, edited by T. Skalinski (Panstwowe Wydawnictwo Naukowe, Warsaw, 1969), p. 403.

dJ. Duperier, Diplom. Et. Sup. Paris (1966).

${ }^{\circ}$ E. Bernabeu, Rev. Acad. Cienc. Exactas Fis. Quim. Nat. Zaragoza.

density of the buffer gas, and $\eta(\rho)$ is the phase change caused by a collision.

For the impact approximation, and assuming that the atoms move in classical straight paths one obtains

$$
\eta(\rho)=\frac{63 \pi}{256} \frac{C_{12}}{\hbar \bar{v}} \rho^{-11}-\frac{3 \pi}{8} \frac{C_{6}}{\hbar \bar{v}} \rho^{-5} .
$$

The validity range of the impact approximation for the Lennard-Jones (12-6) potential is determined by $^{19}$

$$
\gamma \ll(\bar{v} / 2 \pi \sqrt{\pi c})\left(C_{6} / C_{12}\right)^{1 / 6} .
$$

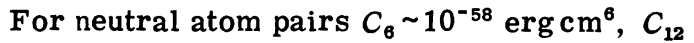
$\sim 10^{-102} \mathrm{erg} \mathrm{c} \mathrm{m}^{12}$, and $\bar{v} \sim 10^{5} \mathrm{~cm} \mathrm{sec}^{-1}$. With these values, we find that the condition (6) is $\gamma \ll 6.45$ $\mathrm{cm}^{-1}$. This condition is largely fulfilled by all our experimental results.

The path described by the colliding atoms can influence the results for shift and broadening. In particular, if the interaction potential between these atoms is much smaller than the kinetic energy, the path can be considered as straight. This condition is verified in the applicability range of semiclassical theory.

A qualitative calculation can be made in order to 
TABLE IV. Summary of results for $C_{6}$ and $C_{12}$ for $D_{1}, D_{2}$ lines of $\mathrm{Cs}$ in $\mathrm{He}, \mathrm{Ne}, \mathrm{Ar}, \mathrm{Kr}$, $\mathrm{Xe}, \mathrm{H}_{2}$, and $\mathrm{N}_{2}$. $\left(C_{6}\right.$ and $C_{12}$ are in units of $10^{-58} \mathrm{erg} \mathrm{\textrm {cm } ^ { 6 }}$ and $\left.10^{-102} \mathrm{erg} \mathrm{cm}^{12}\right)$.

\begin{tabular}{|c|c|c|c|c|c|}
\hline \multirow[b]{2}{*}{ System } & \multicolumn{2}{|c|}{$D_{1}(8943 \AA)$} & \multicolumn{2}{|c|}{$D_{1}(8521 \AA)$} & \\
\hline & $C_{6}$ & $C_{12}$ & $C_{6}$ & $C_{12}$ & \\
\hline $\mathrm{Cs}-\mathrm{He}$ & $\begin{array}{c}0.87 \pm 0.26 \\
0.37 \\
0.76 \\
-1.04\end{array}$ & $\begin{array}{c}-0.245 \pm 0.31 \\
40.0 \\
-0.43\end{array}$ & $\begin{array}{c}0.66 \pm 0.28 \\
0.42 \\
-0.32 \\
-0.43\end{array}$ & $\begin{array}{c}-3.38 \pm 0.61 \\
-2.12\end{array}$ & $\begin{array}{l}\text { Ref. } 22^{\mathrm{a}} \\
\text { Ref. } 21^{\mathrm{a}} \\
\text { Ref. } 23^{\mathrm{b}}\end{array}$ \\
\hline $\mathrm{Cs}-\mathrm{Ne}$ & $\begin{array}{c}1.57 \pm 0.28 \\
0.71 \\
1.66 \\
0.91\end{array}$ & $\begin{array}{c}34.0 \quad \pm 5.6 \\
340.0 \\
11.0\end{array}$ & $\begin{array}{c}0.64 \pm 0.13 \\
0.81 \\
-0.52 \\
1.2\end{array}$ & $\begin{array}{c}0.76 \pm 0.36 \\
-19.67 \\
11.0\end{array}$ & $\begin{array}{l}\text { Ref. } 22^{a} \\
\text { Ref. } 21^{a} \\
\text { S. Y. Ch'en }{ }^{b_{b} c}\end{array}$ \\
\hline $\mathrm{Cs}-\mathrm{Ar}$ & $\begin{array}{c}5.40 \pm 0.38 \\
2.94 \\
7.49 \\
20.0\end{array}$ & $\begin{array}{c}84.22 \pm 15.1 \\
143.76 \\
8400\end{array}$ & $\begin{array}{c}4.73 \pm 0.65 \\
3.35 \\
-0.41 \\
\\
3.85\end{array}$ & $\begin{array}{r}55.20 \pm 8.60 \\
-3.41 \\
7.69\end{array}$ & $\begin{array}{l}\text { Ref. } 22^{\mathrm{a}} \\
\text { Ref. } 21^{\mathrm{a}} \\
\text { S. Y. Ch'en }{ }^{\mathrm{b}, \mathrm{c}} \\
\text { Ref. } 23^{\mathrm{b}}\end{array}$ \\
\hline $\mathrm{Cs}-\mathrm{Kr}$ & $\begin{array}{c}13.16 \pm 0.53 \\
4.44 \\
12.19\end{array}$ & $\begin{array}{l}16360 \\
243.86\end{array}$ & $\begin{array}{c}7.29 \pm 0.42 \\
7.14 \\
0.55\end{array}$ & $\begin{array}{r}461.8 \pm 20.5 \\
3.279\end{array}$ & $\begin{array}{l}\text { Ref. } 22^{\mathrm{a}} \\
\text { Ref. } 21^{\mathrm{a}}\end{array}$ \\
\hline $\mathrm{Cs}-\mathrm{Xe}$ & $\begin{array}{c}9.18 \pm 0.31 \\
7.19 \\
20.90 \\
9.2\end{array}$ & $\begin{array}{c}423.348 \\
11.8\end{array}$ & $\begin{array}{r}249.27 \\
11.59 \\
3.74\end{array}$ & $\begin{array}{r}9.89 \times 10^{6} \\
-2.74\end{array}$ & $\begin{array}{l}\text { Ref. } 22^{a} \\
\text { Ref. } 21^{a} \\
\text { Ref. } 23^{b}\end{array}$ \\
\hline $\mathrm{Cs}-\mathrm{H}_{2}$ & $-2.16 \pm 0.71$ & $29.52 \pm 82$ & $3.35 \pm 0.64$ & $56.9 \pm 10.1$ & \\
\hline $\mathrm{Cs}-\mathrm{N}_{2}$ & $26.91 \pm 0.43$ & 26760 & $15.10 \pm 0.51$ & 17460 & \\
\hline
\end{tabular}

${ }^{a}$ Theoretical values.

${ }^{\mathrm{b}}$ Experimental value.

${ }^{\mathrm{c}} \mathrm{S}$. Y. Ch'en, in Proceedings of the International Conference on Optical Pumping and Atomics Lines Shape, edited by T. Skalinski (Panstwowe Wydawnictwo Naukowe, Warsaw, 1969), p. 403.

estimate the range of applicability of the straightpath approximation. The orbit will be significantly curved if the impulse of the force exerted between the colliding atoms becomes of the order of the momentum of either of them. The relevant ratio $p$ is therefore

$$
p \sim(6 / \mu)\left(\hbar / \bar{v}^{4} C_{6}\right)^{1 / 5},
$$

if $p \sim 1$ the path is significantly curved and it is necessary to use the quantum theory of Baranger..$^{20}$ If $p \ll 1$ the path is practically unaltered and the semiclassical theory can be used. Substituting in expression (7) the typical values of $C_{6}$ for the systems of our interest leads to the following values:

$\begin{array}{cccccccc}\text { Gas } & \mathrm{He} & \mathrm{Ne} & \mathrm{Ar} & \mathrm{Kr} & \mathrm{Xe} & \mathrm{H}_{2} & \mathrm{~N}_{2} \\ p & 0.2 & 0.06 & 0.01 & 0.009 & 0.006 & 0.3 & 0.02\end{array}$

From these considerations, we analyze our experimental results using the semiclassical theory of Lindholm-Foley for all the systems studied by us except for $\mathrm{Cs}-\mathrm{He}$, and $\mathrm{Cs}-\mathrm{H}_{2}$ where we use the quantum theory of Baranger. In Table IV we show the calculated values of the interatomic potential constants for the $D_{1}, D_{2}$ lines of Cs interacting with the different buffer gases. For Cs-noble gas systems our values of the $C_{6}$ constant for the $D_{1}$ line are in agreement with the theoretical values obtained by Baylis ${ }^{21}$; for the $D_{2}$ line such values are in agreement with the theoretical values of Mahan $^{22}$ and the empirical values of Jacobson. ${ }^{23}$ The values of the constant $C_{12}$ are in disagreement among all the authors, ${ }^{21,22,23}$ but the values of this constant have very little influence on the shifts and broadenings of the lines in the theories employed by us.

\section{SHIFT AND BROADENING OF THE HYPERFINE COMPONENTS OF $D_{1}$ LINE}

The general theory of collision broadening and shift of the hfs components of atomic spectral lines has been developed by $\mathrm{Omont}^{24}$ and Rebane. ${ }^{25}$ The shift and broadening of the hyperfine components are determined by the eigenvalues of the collisional relaxation matrix of the electronic-nuclear multipole moments. If we consider the transition $j=\frac{1}{2}-j^{\prime}=\frac{1}{2},\left(D_{1}\right.$ line $)$ we find for the impact ap- 
TABLE V. Theoretical and experimental values of shift and broadening of hfs components of $D_{1}$ line of $\mathrm{Cs}$ in Cs-gas system (in units of $10^{-3} \mathrm{~cm}^{-1} /$ Torr).

\begin{tabular}{|c|c|c|c|c|}
\hline \multirow[b]{2}{*}{ System } & \multicolumn{2}{|c|}{ Broadening } & \multicolumn{2}{|c|}{ Shift } \\
\hline & Theoretical $^{\mathrm{a}}$ & Experimental & Theoretical $^{\mathrm{a}}$ & Experimental \\
\hline $\mathrm{Cs}-\mathrm{Ar}$ & 0.5 & $0.66 \pm 0.04$ & -0.18 & $-0.29 \pm 0.03$ \\
\hline $\mathrm{Cs}-\mathrm{Kr}$ & 0.51 & $0.66 \pm 0.08$ & -0.18 & $-0.29 \pm 0.01$ \\
\hline $\mathrm{Cs}-\mathrm{Xe}$ & 0.57 & $0.72 \pm 0.09$ & -0.21 & $-0.27 \pm 0.04$ \\
\hline
\end{tabular}

${ }^{a}$ Reference 25 .

proximation two purely electronic constant relaxations, and if very weak magnetic interactions are neglected one obtains ${ }^{24}$ an equal value for the shift and broadening in both hfs components.

In $T$ able $V$ we show the theoretical values of shift and broadening of the hfs components of the $D_{1}$ line of cesium-heavy noble gas systems calculated by Rebane. ${ }^{25}$ These values are somewhat lower than the ones calculated by us by a weighted average from our experimental results for the $\left(i_{+}, i_{-}\right)$components of the $D_{1}$ line. ${ }^{26}$ The experimental shift shown for the Cs-Kr system corresponds only to the $i$ - component, because the experimental values for the two hfs components are in disagreement. For other systems measured by us $\left(\mathrm{Cs}-\mathrm{He}, \mathrm{Cs}-\mathrm{Ne}, \mathrm{Cs}-\mathrm{H}_{2}\right.$, and $\left.\mathrm{Cs}-\mathrm{N}_{2}\right)$ the values for the shift and broadening of hfs $\left(i_{+}, i_{-}\right)$components, are also in disagreement, but they are not shown in the table.
${ }^{1}$ For a review see S. Y. Ch'en and M. Takeo, Rev. Mod. Phys. 29, 20 (1957); and R. G. Breene, Sr., The Shift and Shape of Spectral Lines (Pergamon, New York, 1963), among others.

${ }^{2}$ (a) S. Y. Ch'en and R. O. Garret, Phys. Rev. 144, 59 (1966); (b) R. O. Garret and S. Y. Ch'en, ibid. 144, 66 (1966); (c) S. Y. Ch'en, E. C. Looi, and R. Garret, ibid. 155, 38 (1967); (d) R. O. Garret, S. Y. Ch'en, and E. C. Looi, ibid. 156, 48 (1967); (e) S. Y. Ch'en, D. E. Gilbert, and D. K. L. Tan, ibid. 148, 51 (1960); (f) D. E. Gilbert and S. T. Ch'en, ibid. $\overline{188}, 40$ (1969); (g) F. Rostas and J. L. Lemaire, J. Phys. B $\underline{4}, 555$ (1971).

${ }^{3}$ S. Y. Ch'en, E. L. Lewis, and D. N. Stacey, J. Phys. B 2, 275 (1969).

${ }^{4} \mathrm{Y} . \overline{\mathrm{V}}$. Evdokimov, Opt. Spektrosk. $\underline{24}, 832$ (1968) [Opt. Spectrosc. (USSR) 24, 448 (1968)].

${ }^{5}$ G. Smith, J. Phys. B $\underline{8}, 2273$ (1975).

${ }^{6}$ E. Bernabeu, F. Garcia Peralta, and J. M. Alvarez, J. Opt. Soc. Am. 67, 241 (1977).

${ }^{7} \mathrm{~J}$. M. Alvarez, Ph.D. thesis, University of Zaragoza, Spain, 1977 (unpublished); E. Bernabeu and J. M. Alvarez, in Proceedings of the Eleventh Congress of the International Commision for Optics, edited by J. Bescós, A. Hidalgo, L. Plaza, and J. Santamaria (Sociedad Española de Optica, Madrid, 1978), p. 476.

${ }^{8}$ E. Bernabeu and J. M. Alvarez, Opt. Pur. Apl. 12, 113 (1979).

${ }^{9} \mathrm{~J}$. M. Alvarez and E. Bernabeu, Opt. Pur. Apl. 11, 99 (1978).

${ }^{10}$ The experimental fits of these absorption coefficients to a Voigt profile give a standard deviation of $\sim 6 \times 10^{-4}$.

${ }^{11}$ O. S. Heavens, J. Opt. Soc. Am. 10, 1058 (1961); J. K.
Link, ibid. 9 , 1195 (1966).

${ }^{12}$ C. L. Chen and A. V. Phelps, Phys. Rev. 173,62 (1968).

${ }^{13}$ For the pressure range employed, the theoretical predictions give a linear dependence of the shift and broadening with the pressure.

${ }^{14}$ D. A. Jackson, Proc. R. Soc. London 147, 2095 (1969);

H. Kleiman, J. Opt. Soc. Am. 52, 441 (1961).

${ }^{15}$ R. Granier, J. Granier, and F. Schuller, J. Quant. Spectrosc. Radiat. Transfer 16, 143 (1976).

${ }^{16} \mathrm{~J}$. F. Kielkopf, J. Phys. B 9 , L547 (1976).

${ }^{17}$ E. Lindholm, Ark. Mat. Astron. Fys. 32A, 17 (1945);

H. M. Foley, Phys. Rev. 69 , 616 (1946).

${ }^{18} \mathrm{~W}$. Behmenburg, J. Quant. Spectrosc. Radiat. Transfer 4, 177 (1964); W. R. Hindmarsh, A. D. Petford, and

G. Smith, Proc. R. Soc. London 247, 296 (1967).

${ }^{19} \mathrm{~W}$. R. Hindmarsh and J. M. Farr, Progress in Quantum Electronics (Pergamon, New York, 1973).

${ }^{20}$ M. Baranger, Phys. Rev. 111, 494 (1958); 111, 481 (1958).

${ }^{21}$ W. E. Baylis, J. Chem. Phys. 51, 2665 (1969); JILA, Report No. 100, University of Colorado, 1969 (unpublished).

${ }^{22}$ G. D. Mahan, Chem. Phys. $\underline{50}, 2735$ (1969).

${ }^{23}$ (a) H. C. Jacobson, Phys. Rev. A $\underline{4}, 1363$ (1971); (b)

4, 1368 (1971).

${ }^{24}$ A. Omont, J. Phys. (Paris) 34, 179 (1973).

${ }^{25}$ V. N. Rabane, Opt. Spektrosk. 41, 372 (1976) [Opt. Spectrosc. (USSR) 41, 214 (1976)]; Opt. Spektrosk. 41, 894 (1976) [Opt. Spectrosc. (USSR) 41,526 (1976)].

${ }^{26} \mathrm{This}$ can be due, in part, to the fact that the interatomic potential considered has only a van der Waals term. 